\title{
The Application of Structural Equation Modelling for Predicting the Link between Motivation and Experience Quality in Creative Tourism
}

\author{
Dwi Suhartanto ${ }^{1, *}$, Regina Agustina ${ }^{2}$, Nono Wibisono ${ }^{1}$, Gundur Leo ${ }^{1}$ \\ ${ }^{1}$ Department of Business Administration, Politeknik Negeri Bandung, Bandung, Indonesia \\ ${ }^{2}$ Department of Business Administration, Widyatama University, Bandung, Indonesia
}

\begin{abstract}
The Indonesian creative tourism industry is growing and competitive. In this competitive industry, the tourism attraction capability in delivering a quality of experience and motivating customers to visit is imperative. However, research to explore tourist motivation impact on experience quality in creative tourism is limited. This paper is designed to predict the influence of motivation on experience quality in the creative tourism by applying Structural Equation Modelling (SEM). Data were collected through survey from 260 tourists visiting creative tourism attractions in Bandung. The result shows that push motivation has a significant impact on experience quality dimension of escape, learning, and recognition; while the impact of pull motivation is not significant. This finding improves the theoretical and managerial understanding on the link between motivation and experience quality as well as the application of SEM in creative tourism industry.
\end{abstract}

\section{Introduction}

Tourism industry, especially creative tourism, is one of the growing and a competitive industry [1]. In this dynamic and competitive environment, creative tourism destinations face a stiff competition as numerous destinations present similar attractions [2]. Further, in this unique tourism industry, tourists expect more than a good service experience [3], for both the new and the returning tourists. As returning customers yield higher than new customers due to less marketing expenditure, acquiring new tourists should be a continuing task. For this task, creative tourism managers have to comprehend the factors that create such a favourable behaviour [4].

The literature in services context has reported that there are several factors affecting tourist experience with the attraction, including, among others, customer expectation, past experience, customer image on the attraction, and tourist characteristics [5]. Further, recent studies have identified that motivation has an impact on tourist perception on the quality of the service in various service industries [6]. However, limited studies have assessed motivation as an experience quality determinant in creative tourism. Additionally, a limited

\footnotetext{
* Corresponding author: dwi.suhartanto@polban.ac.id
} 
study in creative tourism attraction applies structural equation modelling (SEM) as a comprehensive analysis method.

This paper extends the existing experience quality literature by focusing on creative attractions, which can be challenging as such an experience may initially be considered as a once-in-a-lifetime experience. More specifically, this study is intended to (1) examine the effect of tourists' motivation on their experience with the quality of the attraction, and (2) apply structural equation modelling to predict the association between motivation and experience quality.

\section{Literature review}

The service experience concept has attracted attention among scholars [7], however, studies related to the service experience suggest that what the meaning of service experience is still lack of agreement [8]. As part of the service experience, the consumption experience is articulated by a sense of fun and fantasy [7]. This notion suggests that the experience of the service is not only during the customers encounter with the service, but also when the customers communicate and interact with the service providers. In tourism, experience quality refers to tourists' psychological and social response towards the consequence of the service performance during their visit and consume the service attraction [9]. This notion implies that experience quality is different from service quality which reflects the evaluation of the service consumption [10].

The literature identifies various dimensions of experience quality. Pine and Gilmore [7] introduce a measurement scale of 4E (educational, entertainment, escapist, and aesthetic) to assess experience in the accommodation industry. While in the tourism context, $\mathrm{Xu}$ and Chan [11] present dimension of peace of mind, relaxation, involvement, recognition, escape, and hedonics. These researchers use different dimensions but have a relatively similar concept that renders tourist participation as the main factor. Past studies report that tourist intention to revisit and recommend an attraction is an impact of customer experience with the performance. Further, literature also informs that tourist experience quality has a positive consequence on tourist behaviour toward attraction such as their level of satisfaction and loyalty as well as their memories [12, 13]. While past studies were conducted in the general attraction arena, as far as the authors' knowledge, no research has been undertaken in the creative attraction context.

The reason why people travelling is one of the earliest focus of study in tourism research $[14,15]$. Past studies identify that motivation is not only enabling to rationalize a certain tourist behaviour, but it is also a pivotal factor in influencing tourist post-purchase behaviour $[4,16]$. There are many definitions given to the term of motivation in tourism context which one of generally accepted refers to a combination of traveller wants and need that influence a person propensity to visit and enjoy the destination attractions [17]. This propensity is the only factor rationalizing the reason for a certain traveller behaviour [4]. Many theories have explained motivation, but the push-pull theory is the most commonly applied theory to explain tourist travel behaviour [18]. As named, the push-pull theory explains motivation using a two-dimensional perspective; a push factor is a person's internal wants such as the need to have fun, relax, or break from routine life; while a pull factor is the attributes of destination such as attractions, entertainment performances, restaurants, art galleries and so on which attracts a person to visit. In short, push motivation represents what tourist is seeking when visiting a destination, while pull motivation represents the destination offering to satisfy tourists' needs in travelling. It is expected that in a tourist attraction, both pull and push factors affect tourist experience with the creative tourism attraction, leading to hypothesis (H1): Pull motivation influences the experience quality dimension and (H2): Push motivation influences the experience quality dimension. 


\section{Method}

The data were collected by using a self-administrated questionnaire from 260 tourists at four creative tourism destinations in Bandung. This number of data is adequate to test the simple proposed model [19]. Specifically, the destinations are Saung Angklung Udjo, Batik Komar, Daarus Sunnah Horse Riding and Archery, and Eco Bambu Cipaku. The data consists of females $(56.2 \%)$ and males $(43.8 \%)$ respondents with the majority $(62.7 \%)$ were under the age of 40 . The experience quality consists of three variables (escape, learning, and recognition) with 12 indicators (see Table 1). The motivation consist of two constructs, pull and push motivation with each consists of three indicators adopted from preceding researches [3]. All variables were gauged by 5-point Likert measurement scale, from "strongly disagree" to "strongly agree". To test the hypotheses, this research uses Structural Equation Modelling (SEM). The validity and reliability of the scale measurement constructs were examined by applying confirmatory factor analysis. This method was also used to verify the proposed model. SEM enables a researcher to assess latent construct and testing the relationships between the variables simultaneously [19]. Additionally, SEM is a noted technique to estimate coefficient paths of structural models.

\section{Result}

The measurement model of the link between motivation and experience quality was evaluated by employing confirmatory factor analysis (CFA) with the assumption that all of

Table 1. Reliability and Validity Check.

\begin{tabular}{|l|c|c|}
\hline Construct/Item & CR & AVE \\
\hline Escape (EQ1) & 0.764 & 0.52 \\
\hline - Forget daily activity (E1) & & \\
\hline - Escape from routine (E2) & & \\
\hline - Comfortable (E3) & & \\
\hline - Relaxing (E4) & & \\
\hline Learning involvement (EQ2) & 0.783 & 0.55 \\
\hline - Involve in the activity (L1) & & \\
\hline - Get a unique experience (L2) & & \\
\hline - Can choose the activity (L3) & & \\
\hline - Increase knowledge (L4) & & \\
\hline - Increase expertise (L5) & & \\
\hline - Understand something new (L6) & & \\
\hline Recognition (EQ3) & 0.799 & 0.67 \\
\hline - Treated as an important person (R1) & & \\
\hline - Treated wholeheartedly (R2) & & \\
\hline Push Motivation (PUSH) & 0.786 & 0.65 \\
\hline - Find a new experience (M1) & & \\
\hline - Enjoy the holiday (M2) & & \\
\hline - Refresh from daily activity (M3) & & \\
\hline Pull Motivation (PULL) & 0.822 & 0.7 \\
\hline - Accompany friend/family (M4) & & \\
\hline - Passing by the attraction (M5) & & \\
\hline - Attracted by the promotion (M6) & & \\
\hline
\end{tabular}
the variables tested co-vary each other. The CFA test result indicates that the goodness-of-fit index of the model is poor (CMIN/DF: 3.484, GFI: 0.879 , CFI: 0.876, and RMSEA: 0.083).

In order to make the model fit, the next step modifies the variables by re-parameterizing based on the standardized residual, insignificant path, and modification index value with theoretical concept consideration [19]. Using this process, indicators from motivation variables (M1 and M4), Escape variable (E3), and Learning variable (L1, L2, L3) we excluded from the model. Excluding these items resulting that the constructs are valid and reliable, indicated by the value of composite reliability higher than 0.7 and the value of average variance extracted also higher than 0.5 [19]. Additionally, the requirement for discriminant validity is also met as the value of average variance extracted is higher than the constructs squared 
correlation [19].

Following the validity and reliability check, the test of the proposed model was performed to analyse the hypothesized causal paths between variables. The result of the modified model shows that the requirements of goodness-of-fit indexes are satisfied (CMIN/DF: 3.15, GFI: 0.930, CFI: 0.931, and RMSEA: 0.077). In addition, the result of

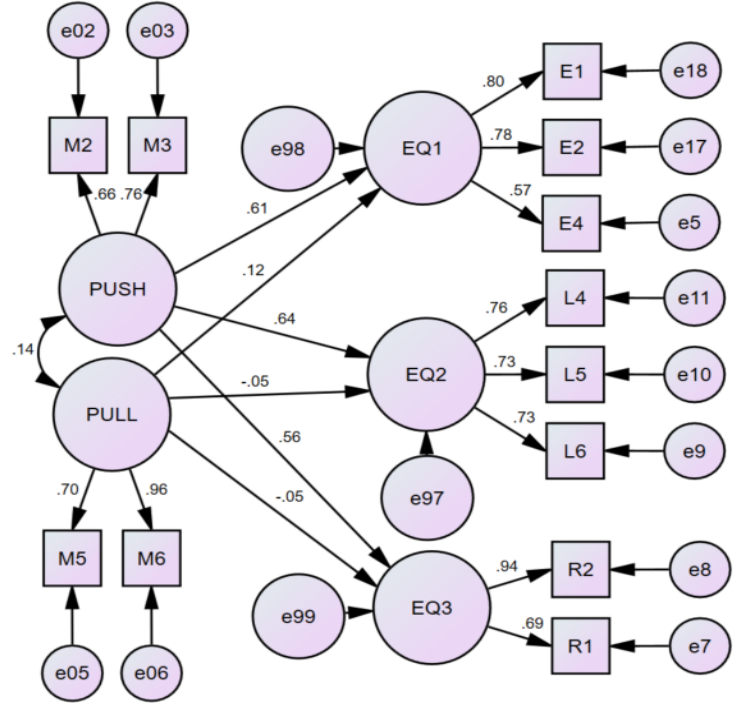

Fig 1. Result of testing the model. model testing indicates that the estimation model by using bootstrapping is satisfactory as there are no estimation problems occurred.

The testing model results notes that this study reveals the association between push and pull motivation and three dimensions of experience quality. The effect of push motivation on all of the experience quality dimensions, escape, learning, and recognition $(0.610,0.648$, and 0.568 respectively) is significant at $p<0.01$. In contrast, the effect of pull motivation on experience quality dimension is not significant. Thus, the results of testing hypothesis show that hypothesis $\mathrm{H} 1$ is supported, while hypothesis $\mathrm{H} 2$ is not supported.

The study results extend the result of past studies $[20,21]$ which report the importance of motivation on quality, satisfaction and loyalty. The result reveals the effect of push motivation factor in influencing tourist experience with the performance of the attraction. The positive association between push motivations on tourist experience quality implies that the more tourists are motivated by the push factor, the more they perceived a high quality of the attraction performance; while less pull motivation will not impact on tourist experience with the attraction performance. In addition, this finding uncovers that the effect of push motivation toward the learning dimension of experience quality is the highest compared to that of the other dimensions. Thus, this study stresses the push factors as a critical determinant of experience quality, mainly on the learning dimension.

The testing of proposed model on the link between motivations on experience quality in creative tourism shows the strength of using the SEM to examine a complex model including constructs with many indicators. Using this method, a researcher can simultaneously inspect the validity, reliability, fitness of the model and relationships between the variables. Compared to other methods such as multiple regression which is commonly used in analysing the variables relationship in creative tourism study, this method clearly can help the researcher understand the relationship between the variables tested comprehensively.

\section{Conclusion, Implication, and Future Research}

Although creative tourism is a promising sector, studies to scrutinize tourist motivation in relation to tourist experience with the creative tourism attraction is limited. This research examines the creative attraction motivation and its impact on three experience quality, 
namely escape, learning, and recognition. The data analysis reveals a positive effect of push motivation on three dimensions of experience quality. Theoretically, this finding offers a solid support for the argument of the relationship between motivation and customer experience with the service, where motivation is an important determinant of customer service experience. However, in terms of pull motivation, this research suggests that this factor has less importance as a determinant of experience quality. Further, the positive linkage between push factor and experience quality dimension highlights the effect of push factor on attraction experience. Considering other studies reporting a positive effect of motivation on satisfaction and loyalty $[6,16]$, these findings implies that the experience quality consequences of motivation extends our understanding that, besides experience quality, satisfaction, and perceived value, motivation, especially push factor is also one of the tourist loyalty building blocks in creative tourism attraction. Lastly, this study offers an evidence of a better analysis method of using SEM compared to regression analysis to examine a research model in creative tourism.

The results of this study bear implications for managing and marketing creative attractions. It reveals that push motivation is an important determinant of experience quality. To attract and develop visitor experience, the attraction managers need to develop customer pushing motivation strategy. Developing appropriate pricing and marketing strategies may not be necessary. To attract customers, it is important that the creative attraction managers to stressing on the benefit that the attraction to offer, that is to provide a new learning and enjoying the experience. Further, collaborative promotions with other tourist attractions and destination organizations to attract visitors to the destination by stressing the benefit of the experience with attraction offered are important, as tourists generally also enjoy visiting other city' attractions.

While this paper reveals some important findings, it does have limitations. First, the data was gathered from four cultural-based attractions located in Bandung, Indonesia which essentially hampers the generalization of the findings. This issue of generalization can be solved with replication of this research in a different destination with a different culture. Replication such a study can also focus on different tourists, for instance between domestic and foreign tourists. Second, in addition to experience quality, motivation has a direct consequence on visitor satisfaction and loyalty, it is also critical to include these variables on the model of the link between motivation and experience quality, such as tourism involvement which is an important factor for the employee to serve tourists better [22].

\section{References}

1. D. Suhartanto, "The role of store coopetition and attractiveness on the performance of tourism destination and its retail stores," International Journal of Tourism Policy, 7, pp. 151-165 (2017)

2. H. Zhang, X. Fu, L. A. Cai, and L. Lu, "Destination image and tourist loyalty: A metaanalysis," Tourism Management, 40, pp. 213-223 (2014)

3. D. Suhartanto, A. Brien, N. Sumarjan, and N. Wibisono, "Examining attraction loyalty formation in creative tourism," International Journal of Quality and Service Sciences, 10, pp. 163-175 (2018)

4. L.-L. Chang, K. F. Backman, and Y.-C. Huang, "Creative tourism: a preliminary examination of creative tourists' motivation, experience, perceived value and revisit intention," International Journal of Culture, Tourism and Hospitality Research, 8, pp. $401-419$ (2014)

5. R. Dodds and L. Jolliffe, "Experiential Tourism: Creating and Marketing Tourism Attraction Experiences," in The Handbook of Managing and Marketing Tourism 
Experiences, M. Sotiriadis and D. Gursoy, Eds., ed Bingley, UK: EmeraldInsight, pp. 113-129 (2016)

6. A. Subrahmanyam, "Relationship between service quality, satisfaction, motivation and loyalty: a multi-dimensional perspective," Quality Assurance in Education, 25, pp. 171-188 (2017)

7. B. J. Pine and J. H. Gilmore, "Welcome to the experience economy," Harvard Business Review, pp. 97-105 (1998)

8. P. Deshwal, "Customer experience quality and demographic variables (age, gender, education level, and family income) in retail stores," International Journal of Retail \& Distribution Management, 44, pp. 940-955 (2016)

9. C.-F. Chen and F.-S. Chen, "Experience quality, perceived value, satisfaction and behavioral intentions for heritage tourists," Tourism Management, 31, pp. 29-35, 2 (2010)

10. D. Suhartanto, "Tourist satisfaction with souvenir shopping: evidence from Indonesian domestic tourists," Current Issues in Tourism, 21, pp. 663-679 (2018)

11. J. Xu and A. Chan, "Service experience and package tours," Asia Pacific Journal of Tourism Research, 15, pp. 177-194 (2010)

12. H. S. Kim and B. Choi, "The effects of three customer-to-customer interaction quality types on customer experience quality and citizenship behavior in mass service settings," Journal of Services Marketing, 30, pp. 384-397 (2016)

13. D. Suhartanto, D. Dean, A. Sosianika, and T. Suhaeni, "Food souvenirs and their influence on tourist satisfaction and behavioural intentions," European Journal of Tourism Research, 18, pp. 133-145 (2018)

14. M. Sundstrom, C. Lundberg, and S. Giannakis, "Tourist shopping motivation: Go with the flow or follow the plan," International Journal of Quality and Services Sciences, 3, pp. 211-224 (2011)

15. C. Antón, C. Camarero, and M. Laguna-García, "Towards a new approach of destination loyalty drivers: satisfaction, visit intensity and tourist motivations," Current Issues in Tourism, 20, pp. 238-260 (2017)

16. C. White, "The impact of motivation on customer satisfaction formation: A selfdetermination perspective," European Journal of Marketing, 49, pp. 1923-1940 (2015)

17. F. Meng, Y. Tepanon, and M. Uysal, "Measuring tourist satisfaction by attribute and motivation: The case of a nature-based resort," Journal of Vacation Marketing, 14, pp. 41-56 (2008)

18. N. K. Prebesen, E. W. Woo, J. S. Chen, and M. Uysal, "Motivation and Involvement as Antecedents of the Perceived Value of the Destination Experience," Journal of Travel Research, 52, pp. 253-264 (2013)

19. J. E. Hair, G. T. Hult, C. M. Ringle, and M. Sarstedt, A Primer on Partial Least Squares Structural Equation Modeling (PLS-SEM), 2 ed. Thousand Oaks: Sage (2017)

20. M. Devesa, M. Laguna, and A. Palacios, "The role of motivation in visitor satisfaction: Empirical evidence in rural tourism," Tourism Management, 31, pp. 547-552 (2010)

21. Y. Yoon and M. Uysal, "An examination of the effects of motivation and satisfaction on destination loyalty: A structural model," Tourism Management, 26, pp. 45-56 (2005)

22. D. Suhartanto, D. Dean, R. Nansuri, and N. N. Triyuni, "The link between tourism involvement and service performance: Evidence from frontline retail employees," Journal of Business Research, 83, pp. 130-137 (2018) 